\title{
Assessment of knowledge towards breast cancer early detection methods among female health professionals in Adigrat town public health institutions, Tigray, northern Ethiopia, 2018
}

\author{
Amdehiwot Aynalem ( $\nabla$ amdayn2011@gmail.com ) \\ Hawassa University https://orcid.org/0000-0001-8436-8504 \\ Andualem Mebratu \\ Dilla University
}

\section{Research note}

Keywords: Knowledge, Breast cancer, Breast cancer early detection

Posted Date: August 21st, 2019

DOI: https://doi.org/10.21203/rs.2.13347/v1

License: (c) (i) This work is licensed under a Creative Commons Attribution 4.0 International License.

Read Full License 


\section{Abstract}

Objective The main objective of the study to determine breast cancer early detection method knowledge among female health professional, Adigrat, town, Tigray, Ethiopia, 2018. Result The study assessed the knowledge of health professionals. Majority of the health professionals $55.7 \%(60)$ were founded knowledgeable and $44.3 \%$ (48) were not knowledgeable.

\section{Background}

Cancer is a group of diseases characterized by the uncontrolled growth and multiply of abnormalcells. If the spread is not controlled, it can result in death (1). Breast cancer (BC) is an explosionof malignant cells that arises in the breast tissue and the term represents a range of disease, from non-invasive to invasive carcinoma (2). One of the most commonly diagnosed cancers worldwide was breast cancer which accounts 1.7 million (11.9\%) of the total, and it is increasing particularly in developing countries where the majority of cases are diagnosed in late stages $(3,4)$. Breast cancer is the first most often occurring among women in Ethiopia. Thousands of more cases unreported as women living in rural areas often seek treatment from traditional healers before seeking help from medical centers (5) Data from the Addis Ababa population based cancer registry showed that breast and cervical cancers were the leading commonly diagnosed cancer comprising $22.6 \%$ and $10.8 \%$ respectively of all cases of cancers in Addis Ababa (6). The causes of breast cancer are not completely known. However, researchers have identified a number of risk factors that increase one's chances of getting breast cancer. These includes; family history of breast cancer, personal history of breast cancer, early menarche, ( $<12$ years), late menopause ( $>55$ years), aging, excessive alcohol use, late age at first full-term pregnancy ( $>30$ years), never breast feeding a child, high fat diet, tobacco smoking, post-menopausal obesity, recent and long term use of hormone replacement therapy, high-dose radiation to chest and lack of physical exercises (2). Breast cancer early detecting is the systematic application of a test in a presumably asymptomatic population. It aims to identify individuals with an abnormality suggestive of cancer. Breast cancer early detection methods include breast self-examination (BSE), clinical breast examination (CBE), and mammography. CBE and mammography require hospital visit and specialized equipment and expertise whereas BSE is an inexpensive tool that can be carried out by women themselves (7). Several studies undertaken to assess the value of mammography for early detection of breast cancer demonstrated a significant reduction in rates of death from breast cancer (about 25\%-30\%) (8). Once breast cancer diagnosed there are specific treatment depends on stage and extent of the tumor. The main treatment options may include: surgery, radiation therapy, biological therapy (targeted drug therapy), chemotherapy and hormone therapy alone or in combination .Many studies have examined the role of female health workers in promoting breast cancer early detection methods $(9,26)$. If this knowledge is poor among those who should teach others, there will be difficulty promoting this life saving methods and it will be a contributing factor for late presentation. Addis Ababa city is selected because it accommodates people with different cultural backgrounds, norms and values and it has a considerable diversity of sociodemographic status and also according to Addis Ababa cancer registry, breast cancer incidence higher 
compared to other areas. Female health workers play a unique role in alerting the community to the early detection of breast cancer methods as they are usually the closest contacts with patients.

This study was designed to evaluate the knowledge, attitude and practice of breast cancer early detection methods among female health workers in Adigrat town, Tigray Ethiopia

\section{Methods}

\section{Study design}

Institution Based Cross Sectional study design was employed

\section{Study area}

Adigrat hospital is a general hospital found in the Eastern Zone of Tigray, Ethiopia. It is a referral hospital for seven (7) primary hospitals and over forty two (42) health centers and health post in the region. It refers patients to Ayder teaching and referral Hospital, the second largest hospital in Ethiopia. It has a catchment area of over one million people. It has over two hundred and eighty (280) staffs, among them three (3) consultants (general surgeon, internist and the gynecologist), six (6) general practitioners, eighty three (83) nurses and 16 midwives from those 97 of them are female health professionals. The hospital has outpatient department, maternity and gynecology wards, surgical ward, one operating theaters, general medical ward, pediatric ward, neonatal intensive care unit (NICU), maternal child health (MCH) clinic, pediatric outpatient, radiology, laboratory, health information management (HIMS), finance, facility management, and kitchen and housekeeping departments. And also from those health center there are two health center in the town Meada agama health center and Tekleswat health center both have included a total of 35 female health professionals

\section{Participant}

All female health professional in Adigrat town public health institutions were considered as source population. The study subjects were female health professionals who was selected and consented to participate in the study.

The sample was determined by using single population formula considering $95 \%$ confidence intervals, and $5 \%$ marginal error. On a research done to assess knowledge of breast cancer and early detection methods among nurses in university hospitals in Addis Ababa $57.8 \%$ of the participants was knowledgeable so taking $P$ value to be 0.578 . The sample size was:-

$\mathrm{P}=0.578$

$Z=1.96$

$d=0.05$ 
$n=(z / 2)^{2} P(1-p)=(1.96)^{2} 0.578(1-0.578)=375$

$d^{2}(0.05)^{2}$

We have to use correction formula since our source of population is less than 10,000

$\mathrm{ni}=\mathrm{n} / 1+\mathrm{n} / \mathrm{N}$

$\mathrm{N}=132$

$\mathrm{n}=375$

$\mathrm{ni}=375 / 1+375 / 132=98$

After adding $10 \%$ non-response rate the final sample size was 108

\section{Instrument}

A self- administered questionnaire were adopted from a research conducted in Addis Ababa public health institutions.

\section{Results}

\section{Socio demographic characteristics of the study population}

The participants were between the age group of 19 - 65 years with a mean age of 29 years and Standard deviation of 6.559 years. By age group, over fifty three of the study Participants (49.1\%) were aged between 29 to 38 years. Most of the participants were married with 79(73.1\%) respondents and single with $22(20.4 \%)$ respondents. $67(62 \%)$ of the study. Participants were first degree holders. From the total study participants 64 (59.3\%) of them were nurses, 10 (9.3\%) were health officers and $24(22.2 \%)$ midwives. The average work experience of the study participants were 2.53 years with standard deviation of 1.357 years, $30(27.8 \%)$ of the participants had worked four and less years, 34 (31.5\%) of the participants had worked for five to nine years and twelve (11.1\%) of the participants had worked for twenty and more years, respectively. Thirteen (12\%) of them mentioned they have history of breast problem while ten $(9.3 \%)$ have reported that they have family history of breast cancer. (Table1)

\section{Knowledge of female health professionals on breast cancer risk factors and sign and symptoms}

Among all of the participants Most of the participants 87 (80.6\%) were mentioned smoking as a risk factor for breast cancer, 74 (68.5\%) mentioned alcohol consumption 49 (45.4\%) mentioned high fat diet, $46(42.6 \%)$ family history of breast cancer. The most commonly mentioned sign and symptom of breast cancer was discharge from the breast 65(60.1\%), dimpling of the breast 64(59.3\%), pain on the breast 63(58.3\%), swelling of the breast 62(57.4\%). (Table 2) 
From all respondents 95(88\%) knew surgery as breast cancer treatment option, 63(58.3\%)

knew Chemotherapy, 63(58.3\%) knew Radiation therapy, 1(0.9\%) mention hormonal therapy and4(3.7\%) don't know breast cancer treatment options

\section{Knowledge of female health professionals on breast cancer early detection methods}

From all of the respondents 56(51.9\%) knew BSE as early detection method, $85(78.7 \%)$ knew

CBE, 58(53.7\%) knew Mammography, and 9(2.3\%) don't know breast cancer early detection

Methods.

\section{Knowledge of respondents on breast cancer early detection methods}

Among all the respondents $29(26.9 \%)$ of them mentioned BSE should be started at twenty years and $51(47.2 \%)$ of them mentioned Mammography should be started at 30 years. $34(31.5 \%)$ of the respondents knew that BSE should be done monthly,9(8.3\%) knew CBE should be done three yearly for women younger than forty, 27 (25\%) mammography yearly. 43(39.8\%) of the respondents answered that appropriate time to perform BSE is one to seven days after menses. Most of the respondents $37(34.3 \%)$ knew that mammography is used for both diagnostic and early detection purpose. (Table 3)

\section{Discussion}

This study tries to assess knowledge towards breast cancer early detection methods. Knowledge of breast cancer was assessed by combining responses regarding risk factor, sign and symptoms, early detection methods and treatment option assessing questions. Work experience of study participants. Age, work experience, marital status and knowledge. In this study smoking was the major risk factor reported for breast cancer, followed by positive family history of breast problem, alcohol consumption and increasing age. Findings in this research similar with researches in Saudi Arabia and Pakistan, increasing age, positive family history of breast problem, smoking were reported as risk factor for developing breast cancer $(29,34)$.

The majority respondents mentioned sign and symptom of breast cancer were discharge from the breast (60.1\%), dimpling of the breast (59.3\%) and pain in the breast (58.3\%). This finding is less than the research finding in Nigeria where breast lump was mentioned by $94.6 \%$, discharge from nipple $89.2 \%$ (22). This could be attributed to the socioeconomic difference may result in increased knowledge about breast cancer sign and symptoms due to higher level of education.

In this study from all the respondents $78.7 \%$ knew CBE as early detection method, $51.9 \%$ knew

BSE and only 33.3\% knew Mammography as a screening method for breast cancer. This study finding is lesser than a study done in government hospitals of Addis Ababa revealed that among female health professionals $77.6 \%$ female health professionals were aware of BSE as early detection method. CBE was 
mentioned as early detection method by $78.7 \%$ and the least mentioned early detection method by the participants was. Mammography which was known by $53.7 \%$ respondents (14). The difference in the result could be attributed to the fact that professionals working in hospitals have more exposure to breast cancer cases and cases are referred to hospitals for further diagnosis and treatment and also experts that have more experience and knowledge are available for consultation. The finding in this research lower than a study done in Nigeria showed that, among the respondents, $97 \%, 93.2 \%, 99 \%$ were aware of breast self-examination, clinical breast examination and mammography as early detection tools respectively (22). This could be attributed to the socioeconomic difference may result in increased knowledge about breast cancer early detection methods due to higher level of education.

In this research among all female health professionals $88 \%$ knew surgery as one of treatment Option, $58.3 \%$ knew radiotherapy as one of treatment option and $58.3 \%$ knew chemotherapy as one of treatment option for breast cancer. This study finding is higher than a research done in central Africa republic showed that among health workers $44.2 \%$ of respondent knew surgery, $22.9 \%$ of respondents knew radiotherapy and $29.7 \%$ of respondents knew chemotherapy as a treatment options. This difference may be due to cultural and socio-economic deference among these two populations (40).

\section{Conclusions}

Based on the finding of this study, the following were concluded, More than half of the health professionals were found knowledgeable regarding breast cancer early detection.

\section{Limitations}

AAHB- Addis Ababa health bureau

BC - Breast Cancer

BCEDM- breast cancer early detection methods

BSE - Breast Self-Examination

CBE - Clinical Breast Examination

KAP - Knowledge, Attitude and Practice

FHW- Female Health Workers

LMCs- Low and Middle Income Countries

UK- United Kingdome

NCR- National Cancer Registry 
NCl- National Cancer Institute

\section{Abbreviations}

AAHB- Addis Ababa health bureau

BC - Breast Cancer

BCEDM- breast cancer early detection methods

BSE - Breast Self-Examination

CBE - Clinical Breast Examination

KAP - Knowledge, Attitude and Practice

FHW- Female Health Workers

LMCs- Low and Middle Income Countries

UK- United Kingdome

NCR- National Cancer Registry

NCl- National Cancer Institute

\section{Declarations}

\section{Competing Interest}

The authors declare no competing interest.

\section{Availability of data and materials}

All generated data are included in this article and its supporting document.

\section{Consent to publish}

Not applicable

\section{Ethics approval and consent to participate}

Ethical clearance was obtained from Institutional Review board of Adigrat University, College of medicine and health sciences. All participants of the study were provided written consent, clearly stating the objectives of the study and their right to refuse. Study participants were also informed that; if they did not want to answer any question, they had the right to do so. All participants were randomly selected without any discrimination. Filled out questionnaires were carefully handled and all access to results was kept 
strictly within the members of the group. Anonymity was maintained to ensure confidentiality of respondents. All participants were provided with Amharic language written consent and put their signature prior to participate in the study.

\section{Acknowledgment}

We would like to thank study participants for their cooperation and assistance during data collection.

\section{Funding}

No Funding was received for this research work.

\section{Authors' contributions}

AA participated in the conception, design of the study, reviewing the proposal, data analysis and report writing. AM participated in data analysis and report writing. AA prepared the manuscript for publication. All authors read and approved the final manuscript.

\section{Author's information}

${ }^{1}$ Hawassa University, College of medicine and health sciences, School of Nursing, Dilla, SNNPR, Ethiopia.

${ }^{2}$ Dilla University, College of medicine and health sciences, Department of Nursing, Dilla, SNNPR, Ethiopia.

\section{References}

1. Mandal A IN, Scott J, Okafor B, Mandal PK, African Americans and Cancer: A Minority Health Advocacy. J Bioproces Biotech 4:e117, 2014.

2. AC Society. Breast Cancer Facts \& Figures. Atlanta. www.iosrjournals.org 2009-2010.

3. International Agency for Research on cancer. Latest world cancer statistics Global cancer burden: WHO: Press release N 223, 2013.

4. Gebrehiwot H HT, Gidey G,. Knowledge and Attitude towards Breast Cancer among Mekelle University Female Regular Undergraduate Students, Tigray Region, Ethiopia, SJAMS 2: 766-772, 2013. 2013.

5. GLOBOCAN (IARC), 2012. Estimated breast cancer incidence and mortality in Ethiopia. International agency for research on cancer. 2012.

6. Saghir,N.S. , Adebamowo, C.A., Anderson, B. O., Carlson, R.W. , Bird P. A., Corbex, 
M., Badwe, R.A., Bushnaq, M. A., Eniu, A. 2011. Breast cancer management in low resource countries (LRCs): Consensus statement from the Breast Health Global Initiative,

The Breast 20 (2011) S3-S11,www.elsevier.com/brst

7. Nasiru A Ibrahim and Olumuyiwa O Odusanya. Knowledge of risk factors, beliefs and practices of female healthcare professionals towards breast cancer in a tertiary institution in Lagos, Nigeria, 2009.

8. Kerlikowske K SP, Phillips KA, Cauley JA, Cummings SR.Continuing screening mammography in women aged 70 to 79 years: impact on life expectancy and cost effectiveness. . JAMA 2001; 282:215663.

9. Olumuyiwa O. Odusanya OOT. Breast Cancer Knowledge, Attitudes and Practice among Nurses, Acta Oncologica. Lagos, Nigeria,. 40:7, 844-848,. 2001.

10. GLOBOCAN 2008 (IARC), CANCER FACT SHEET, Breast Cancer Incidence, Mortality and Prevalence Worldwide in 2008, www@iarc.fr @ IARC 2010

11. GLOBOCAN (IARC) international agency for research on cancer. Estimated breast Cancer incidence, mortality in Ethiopia. Globocan 2012.

12. Addis Ababa city cancer registry in Addis Ababa university blh, radiotherapy center. Breast cancer incidence and death rate in Ethiopia GLOBOCAN 2012.

13. Dye Timothy D, Solomon Bogale, Claire Hobden, Yared Tilahun, Teshome Deressa, and Anne Reeler, 2011. Experience of Initial Symptoms of Breast Cancer and Triggers for Action in Ethiopia. International Journal of Breast Cancer Volume 2012

doi:10.1155/2012/908547.

14. Seife Teferi Dellie TMN, Meaza Demissie, A. Durgaprasada rao. . Knowledge about Breast Cancer Risk-Factors, Breast Screening Method and Practice of Breast Screening Among Female Healthcare Professionals Working In Governmental Hospitals. Addis Ababa, Ethiopia. 2012.

15. Kumar S, Imam, A., Manzoor, N., Masood, N. Knowledge, attitude and preventive Practices for breast cancer among health care professionals at Aga Khan Hospital Karachi, Journal of the Pakistan Medical Association, 2009; 59(7), 474-8. 
16. Communication AJoR. Breast cancer early detection methods. AJRC. 2013; 1(11): 395-

404\} ISSN: 2325-4076.

17. MS. M. Breast cancer. In: Kramer BS, Gohagan JK, Prorok PC, eds. Cancer Screening: Theory and Practice. New York: M. Dekker, 2001; 143-170,

18. Mohammed Yehia Saeedi FAA, Ahmed Khair Ibrahim, Kassim Kassim. . Knowledge,

Attitude and Practice of Breast Cancer Screening among Female General Practitioners in

Riyadh, Saudi Arabia. Cancer Research Journal 2014; Vol. 2, No. 6, pp. 108-113.

19. Santhanakrishnan N, Prabakaran S, Singh Z. Knowledge, attitude, and practice regarding breast cancer and its screening methods among nursing staff working in a tertiary-care hospital located in South India. Int J Med Sci Public Health 2016; 5:1650-1655.

20. Faiza Ahmed, S. M., Juanita Hatcher and Shaista M Khan (2003). "Breast cancer risk factor knowledge among nurses in teaching hospitals of Karachi, Pakistan: a crosssectional study." BMC Nursing 2006, 5:6.

21. Samia Ghanem MG, Siham Elkhoyaali, Mohamed Mesmoudi, Saber Boutayeb, Hassan Errihani,. Knowledge of risk factors, beliefs and practices of female healthcare professionals towards breast cancer, morocco, panafrican medical journal. 2009; ISSN: 1937- 8688.

22. T. O. Bello, A. I. O.-B., A. S. Oguntola, M. L. Adeoti, O. M. Ojemakinde (2011).

Knowledge and Practice of Breast Cancer Screening Among Female Nurses and Lay

Women in Osogbo, Nigeria." West African Journal of Medicine Vol. 30, No. 4

23. Semarya Berhe Lemlem WS, Mignote Hailu, Mesfin Abebe, and Alemseged Aregay. .

Assessment of Knowledge of Breast Cancer and Screening Methods among Nurses in 46

University Hospitals, Addis Ababa, Ethiopia. . ISRN Oncology. 2011; Volume 2013,

Article ID 470981.

24. lidianne alves de sousa e silva1 ymlp, ana izabel oliveira nicolau, knowledge, attitude, and practice of breast self-examination among nursing professionals. 2008.

25. Yeliz Yelen Akpınar ZB, Melis Naçar, İskender Gün, Fevziye Çetinkaya,. Knowledge, Attitude about Breast Cancer and Practice of Breast Cancer Screening among Female 
Health Care Professionals. Asian Pacific Journal of Cancer Prevention, 2011. 2007; Vol 12.

26. Bastani R MAE, Carbonari J, Rozelle R, Baxter J, Vernon S. Breast cancer knowledge, attitudes and behaviours: A comparison of Rural Health and non-health workers,. Cancer

Epidem Biomar 2008; 3:77-85.

27. Oche MO AS, Umar AS Breast Cancer and Mammography: Current Knowledge, Attitudes and Practices of Female Health Workers in a Tertiary Health Institution in

Northern Nigeria,. Public Health Research 2012,. 2008; 2(5): 114-119.

28. Selamawit W/tsadik. Knowledge, Attitude and Practice towards Breast cancer and Breast cancer screening among female Health Professionals in Addis Ababa, 2016.

29. Sheraz Ahmad ANQ, Sania Atta, Mahwish Gul, Muhammad Rizwan, Sohail Ahmad, Ayesha Riaz, Muniba Gul, Shafaq Zaman, Nita Johnny, knowledge, attitude and practice for breast cancer risk factors and screening modalities in staff nurses of ayub teaching Hospital Abbottabad, . J Ayub Med Coll Abbottabad 2011; 23(3). 2011.

30. Mahnoush Reisi, S. H. J., and Gholamreza Sharifirad (2011). "Knowledge, attitudes, and Practice of breast self-examination among female health workers in Isfahan, Iran." pmc.

31. Meryem Yılmaz, T. D. (2014). "Health Beliefs and Breast Cancer Screening Behavior among a Group of Female Health Professionals in Turkey." J Breast Health 2016; 12: 18- 24

32. Jaydip R Oza, J. D. P., Rohit Ram (2008). "A study on awareness toward the early detection of breast cancer on nursing staff in civil hospital, Ahmedabad, Gujarat, India " h e a / $t$ h / i n e ISSN 2229-337X volume 2 Issue 1 January-June 2011.

33. Karima F. Elshamy DNSc, A. M. S. M. (2008). "Knowledge and Practice of Breast

Cancer Screening Among Egyptian Nurses." Afr J Haematol Oncol 2010; 1(4):122-128. 47

34. Shadia Abdullah Yousuf, S. M. A. A., Wafa Nicolas, Hasna and S. M. S. Erfan Banjar

(2011). "Do Saudi Nurses in Primary Health Care Centres have Breast Cancer

Knowledge to Promote Breast Cancer Awareness?" Asian Pacific J Cancer 2012 Prev, 13

(9), 4459-4464.

35. Özgür Erdem1 and Ezzettin Tokta (2014). "Knowledge, Attitudes, and Behaviors about

Breast Self-Examination and Mammography among Female Primary Healthcare Workers in DiyarbakJr, Turkey" BioMed Research International, Volume 2016. 
36. G Ertem, A. K. (2004). "Breast self-examination among nurses and midwives in Odemis health district in Turkey" PMID: 19574672.

37. Central Statistics Agency of Ethiopia. 2007.

38. Bureau AAcaH, c. administrator, Addis Ababa, Ethiopia 2014.

39. Eguvbe AO, Akpede N, Arua N E Knowledge of Breast Cancer and Need for its Screening Among Female Healthcare Workers in Oshimili South Local Government Council Area of Delta State, Nigeria AFRIMEDIC Journal Volume 5, No. 1, January - June, 2014

40. Augustin Balekouzou et al Assessment of Breast Cancer Knowledge among Health Workers in Bangui, Central African Republic Asian Pacific Journal of CancerPrevention, Vol 17, 2016.

\section{Tables}

Table 1: Frequency distribution of socio-demographic characteristics of respondents at Public health institutions in Adigrat town, Tigray, 2018. 


\begin{tabular}{|c|c|c|c|}
\hline Socio demographic variables & \multicolumn{2}{|l|}{ Frequency $n=389$} & Percentage (\%) \\
\hline \multicolumn{4}{|l|}{ Age in years } \\
\hline $19-28$ & \multicolumn{2}{|l|}{31} & 28.7 \\
\hline $29-38$ & \multicolumn{2}{|l|}{53} & 49.1 \\
\hline $39-48$ & \multicolumn{2}{|l|}{18} & 16.7 \\
\hline$\geq 49$ & \multicolumn{2}{|l|}{6} & 5.6 \\
\hline \multicolumn{4}{|l|}{ Profession } \\
\hline health officer & \multicolumn{2}{|l|}{10} & 9.3 \\
\hline Nurse & \multicolumn{2}{|l|}{64} & 59.3 \\
\hline Midwife & \multicolumn{2}{|l|}{24} & 22.2 \\
\hline Other & \multicolumn{2}{|l|}{10} & 9.3 \\
\hline \multicolumn{4}{|l|}{ Level of education } \\
\hline MSc & \multicolumn{2}{|l|}{0} & 0 \\
\hline Degree & \multicolumn{2}{|l|}{67} & 62 \\
\hline Diploma & \multicolumn{2}{|l|}{41} & 38 \\
\hline \multicolumn{4}{|l|}{ Work experience in years } \\
\hline $0-4$ & \multicolumn{2}{|l|}{30} & 27.8 \\
\hline $5-9$ & \multicolumn{2}{|l|}{34} & 31.5 \\
\hline $10-14$ & \multicolumn{2}{|l|}{13} & 12 \\
\hline $15-19$ & \multicolumn{2}{|l|}{19} & 17.6 \\
\hline$>=20$ & \multicolumn{2}{|l|}{12} & 11.1 \\
\hline \multicolumn{4}{|l|}{ Marital status } \\
\hline Single & \multicolumn{2}{|l|}{22} & 20.4 \\
\hline Married & \multicolumn{2}{|l|}{79} & 73.1 \\
\hline Divorced & \multicolumn{2}{|l|}{5} & 4.6 \\
\hline Separated & \multicolumn{2}{|l|}{2} & 1.9 \\
\hline \multicolumn{4}{|l|}{ Self-history of breast problem } \\
\hline Yes & & 13 & 12 \\
\hline No & & & 88 \\
\hline
\end{tabular}




\begin{tabular}{|c|c|c|}
\hline \multirow{2}{*}{\multicolumn{3}{|c|}{ Family history of breast problem }} \\
\hline & & \\
\hline Yes & 10 & 9.3 \\
\hline No & \begin{tabular}{|l|}
98 \\
\end{tabular} & 90.7 \\
\hline
\end{tabular}

Table 2: knowledge of FHP on breast cancer risk factors, sign and symptoms at public health institutions of Adigrat town, Ethiopia, 2018. 


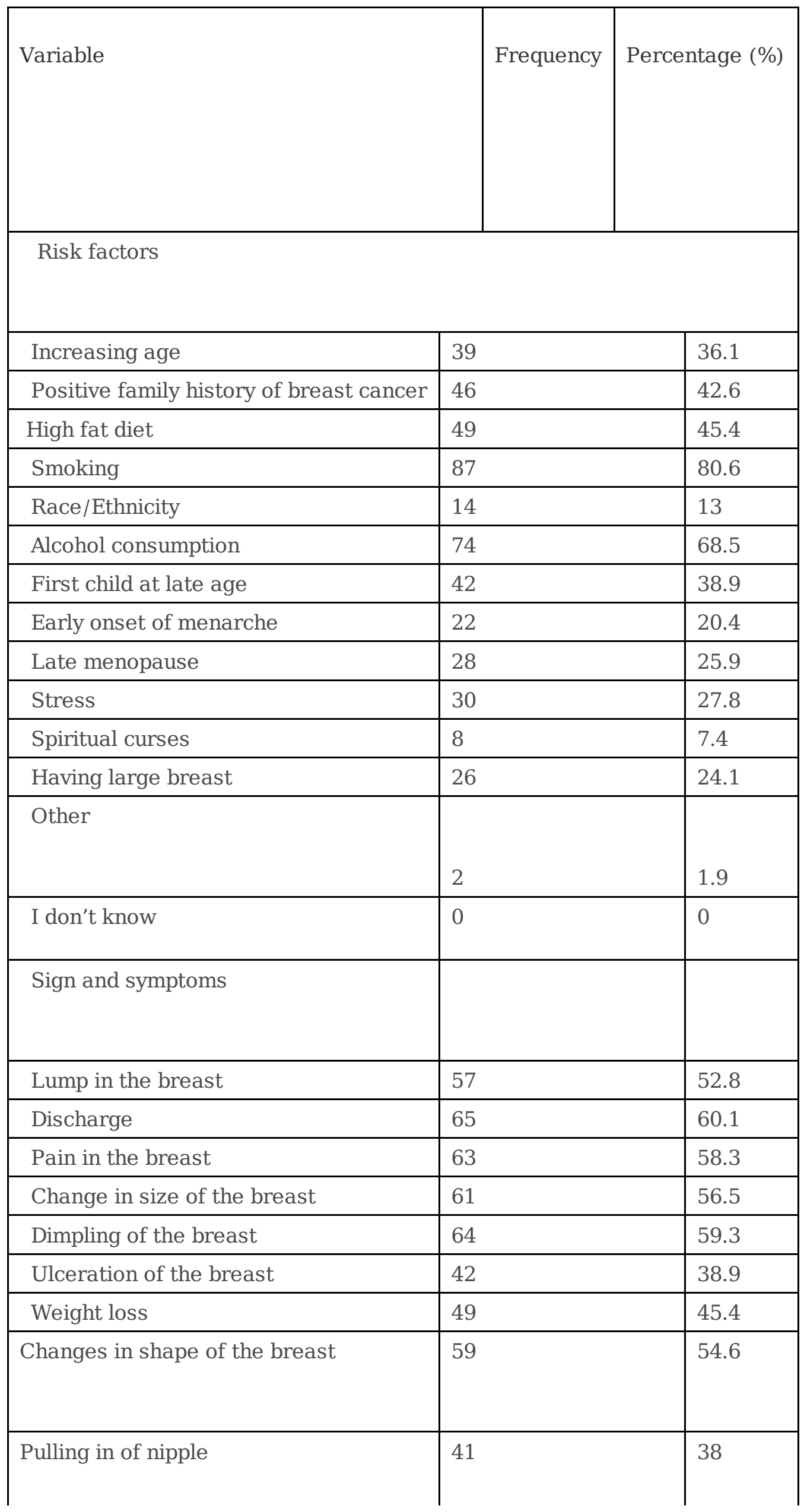




\begin{tabular}{|l|l|l|} 
& & \\
\hline Swelling of the breast & & \\
& 62 & 57.4 \\
\hline Lump under armpit & 45 & 41.7 \\
\hline I don't know & 0 & 0 \\
\hline
\end{tabular}

Table 3: Knowledge of respondents on breast cancer early detection methods at public health institutions in Adigrat town, Tigray, Ethiopia, 2018. 


\begin{tabular}{|l|l|l|l|}
\hline Variable & Frequency & \multicolumn{2}{|}{ Percent (\%) } \\
\hline Recommended age to start BSE & 29 & 26.9 \\
\hline at 20 years & & \\
\hline \multicolumn{2}{|l|}{} & 29 & 11.1 \\
\hline at 40 years & 12 & 44.4 \\
\hline after menarche & 48 & 5.6 \\
\hline after menopause & 6 & 8.3 \\
\hline Other Specify & 9 & 3.7 \\
\hline I don't know & 4 & \\
\hline
\end{tabular}

Frequency of BSE

\begin{tabular}{|l|l|l|}
\hline \multirow{2}{*}{ once in a month } & & \\
& 27 & 25 \\
\hline once in a week & 36 & 33.3 \\
\hline once in three months & 16 & 14.8 \\
\hline Other Specify & 4 & 3.7 \\
\hline I don't know & 25 & 23.1 \\
\hline
\end{tabular}

Appropriate time for performing breast self-examination

\begin{tabular}{|l|l|l|}
\hline During menses & 0 & 0 \\
\hline 1 -7 days before menses & 11 & 10.2 \\
\hline $1-7$ days after menses & 43 & $39 ., 8$ \\
\hline at any time & 27 & 25 \\
\hline Other Specify & 8 & 7.4 \\
\hline I don't know & 19 & 17.6 \\
\hline
\end{tabular}

Frequency of clinical breast examination

\begin{tabular}{|l|l|l|}
\hline Monthly & 34 & 31.5 \\
\hline Once in a year & 26 & 24.1 \\
\hline Every three months & 20 & 18.5 \\
\hline Once in three years & 9 & 8.3 \\
\hline Other Specify & 8 & 7.4 \\
\hline I don't know & 11 & 10.2 \\
\hline Recommended age to start mammography examination & \multicolumn{2}{|l}{} \\
\hline & \multicolumn{2}{l}{} \\
\hline 30 years & 51 & 47.2 \\
\hline 35 years & 23 & 21.3 \\
\hline 40 years & 11 & 10.2 \\
\hline
\end{tabular}




\begin{tabular}{|l|l|l|}
45 years & 3 & 2.8 \\
\hline Other Specify & 3 & 2.8 \\
\hline I don't know & 17 & 15.7 \\
\hline
\end{tabular}

\section{Frequency of mammography}

\begin{tabular}{l|l|l}
\hline once in a year & 27 & 25 \\
\hline every six months & 39 & 36.1 \\
\hline once in two years & 12 & 11.1 \\
\hline once in three years & 7 & 6.5 \\
\hline Other Specify & 1 & 0.9 \\
\hline I don't know & 22 & 20.4 \\
\hline
\end{tabular}

Use of mammography

\begin{tabular}{l|l|l}
\hline For diagnostic purpose & 31 & 28.7 \\
\hline For screening purpose & 36 & 33.3 \\
\hline For both & 37 & 34.3 \\
\hline I don't know & 4 & 3.7 \\
\hline
\end{tabular}

